\title{
Effectiveness of Modular Teaching in Biology at Secondary Level
}

\author{
Riasat Ali (Corresponding author) \\ Institute of Education \& Research \\ University of Science \& Technology, Bannu, (NWFP) Pakistan \\ Tel: 92-0928-621101 E-mail: drriasatali@yahoo.com \\ Safdar Rehman Ghazi \\ Institute of Education \& Research \\ University of Science \& Technology, Bannu, (NWFP) Pakistan \\ Tel: 92-0928-621101Ｅ-mail: drsrghazi@yahoo.com \\ Muhammad Saeed Khan \\ Department of Education \\ HazaraUniversity, Haripur Campus Haripur, (NWFP) Pakistan \\ Tel: 92-03000-830-3638 E-mail: saeedagha@yahoo.com \\ Shukat Hussain \\ Department of Education \\ Hazara University Mansehra, (NWFP) Pakistan \\ Zakia Tanzeela Faitma \\ Institute of Education \& Research \\ University of Science \& Technology, Bannu, (NWFP) Pakistan
}

\begin{abstract}
The major purpose of the study was to explore the impact of modular teaching on the achievements of students. The study was experimental type. Equivalent group study design was used. The collected data of both groups were analyzed and interpreted using mean, standard deviation and t-test, and conclusions were drawn. The results of the study were in the favor of modular teaching approach, therefore, it is suggested that this approach should be widely used in conventional classroom at various levels of education.
\end{abstract}

Keywords: Modular teaching, Effective teaching, Individualized instruction, Self learning, Self study package biology

\section{Introduction}

Education is the only mean through which a society adjusts with its needs. Therefore, a society can never exist without education. Through education, the members of a society learn the skills to enrich, transmit and transform cultural heritage as well as existing social and scientific knowledge for the continuous advancement of the society. Teaching learning process has been inseparable to human being since ancient times. Leaders of human thoughts have endorsed memorable words about education, knowledge and learning. An educational system is explicitly based on the quest, what to teach and how to teach." What to teach "means the learning material. The continuum of learning material swings from linguistic to scientific knowledge. The choice of contents and subject from the multifarious branches of knowledge is subjected to social needs.

According to Johnson and Dalen (1988) there are certain moments in human history when it seems that all human activities and social organizations have been directed towards the extension of knowledge. They further say that 
human endeavors to explore the universe and foster social, cultural and economic needs resulted in a widespread educational system on the global purview. Every society, every culture and every nation is in a race to build up its educational system on profound bases of knowledge, learning and expertise. Today, a nation with superior educational system is superior and dominant.

A module is a specific type of learning resource. Modules are essentially self contained, self-instructional packages, with learning paced by each student according to his/her individual needs and ability. A module covers either a single element of subject matter content or a group of content elements forming a discrete unit of subject matte or area of skill. A module has clearly defined, objectives; preferably in behavioral form (Daries, 1981). Taneja (1989) defined module as a unit of work in a course of instruction that is virtually self-contained and a method of teaching that is based on the concept of building up skills and knowledge in discrete units. A module is a set of learning opportunities organized around a well - defined topic which contains the elements of instruction, specific objectives, teaching learning activities, and evaluation using criterion - referenced measures (UNESCO, 1988).

Most learning packages are entirely individualized but group experiences can be built in it. The main driving force behind the introduction of modules in teaching learning process lies in the fact that they have roles that can help to solve key educational problems. This is largely because they satisfy the basic condition for promoting effective learning and are extremely flexible in implementation. The use of such packages takes into account individual differences and permits students to work at their own pace. That is why Loughran and Berry (2000) pointed out that individuals learnt more at their own pace, because "Telling is not teaching and listening is not learning." But it is a process of first absorbing and then expression of concepts. So it is best achieved by self - learning.

According to Brown et al. (1977) module has following possible advantages in the administration:

(a) Users can study modules within their own environment. This means they can be used not only within teaching institutions but also on the job.

(b) Users can study modules with minimum disruption to their normal duties and responsibilities. While this applies to both students and teachers and it is particularly true for teachers who can use modules as resources for staff development.

(c) Modules may be administered to a single user, small groups or large groups according to need.

(d) Modules programs can be easily revised and upgraded by replacing one module by another amending aspects of a single module.

(e) Module programs are flexible in the sense that they can be implemented through a variety of scheduling patterns.

(f) Modules are economical to use. While initial costs of designed developments are high so they are ultimately cost effective.

\section{Modular Teaching}

Modular teaching is concerned for each pupil as an individual with his own special aptitude and interest, goal of helping each student to think for himself and allowing the individuality to each learner. The emphasis must be on the one-one students with unique abilities, aspiration and influencing experiences and, again to provide quality education, the teacher must personalize and individualize the instructional program. When a teacher devoted to individual learning, he finds time for personal discussion with pupils and giving them individual help. The individual learning may help in developing many notable and self-reliant characters, and in much more modern ways pupils enjoy periods in which they pursue their interests and satisfy their curiosities (Manlove and David, 1985).

\section{Components of Module}

Most of the modules have the following components:

\subsection{Instructions on how to use the module}

The structure of the module needs to be explained, especially if it consists of units. The procedure for working through the module needs to describe and any color-coding explained. Sometimes it is useful to have standard symbols to represent sections such as objectives; input; practice task; feedback and so on. If such symbols are used they need to be defined and explained. What the learner is expected to do during all phases of study should be emphasized. 


\subsection{Purpose and Aims}

By purpose is meant for whom the module is intended and where it fits into a program and a course within a program. It is useful too, to include a curriculum or syllabus grid, which precisely locates the module in the overall course. Aims are broad statement about the types of anticipated learning outcomes such as to develop understanding or to enhance appreciation in some area of knowledge or skill. These statements are important since they clarify for the user and the general areas covered by the module.

\subsection{List of Pre-requisite Skills}

If prior knowledge or skill is needed for achieving the objectives of a module these need to be defined, If, for example, the module is about introductory mechanical drawing it may be necessary for students to know something about basic geometry and have some skill in solving elementary geometrical problems. If so these items should be listed so as to allow for advance preparation for the work of the module itself.

\subsection{List of Instructional Objectives}

This is a critical part of the module. Instructional objectives have to be expressed in behavioral terms that is, in terms of a performance, which can be observed or measured. The objectives of the module as a whole should be listed at the beginning and any units within the module should start with lists of their own specific objectives

\subsection{Diagnostic Pre-test}

Sometimes it is not sufficient to merely list pre-requisite skills and it may be necessary to include a test specifically designed to check whether students have the necessary background to understand the module. If they fail in this test they should be advised on how to catch up by means of reading, solving problems or completing specified practical tasks.

\subsection{Sequenced instructional activities}

These of course, form the "core of the module and set out the input - processing output, or the input - practice task - feedback sequence for each activity in turn. All in text questions self-assessment and feedback quizzes should be included as part of this sequence.

\subsection{Mastery Post - test}

The post-test should have items corresponding one-to-one with the specific objectives of the modules. During trailing phases the post-test or a parallel form of the test should also be included at the beginning of the module so that the modules effectiveness in achieving an educational improvement or gain can be measured. During trailing students answer the questions both before and after completing the module and the difference between their scores gives a measure of gain. Once the module is published in final form, however the "post-test" can be removed from the beginning of the module and be used only to check on final mastery of the objectives.

\subsection{Feedback/Reinforcement}

As the module is self-instructional package it lacks face-to-face interaction between the teacher and the taught. The teacher's role is considered to be in-built in the module. At the final stage when the learner has attempted the mastery post-test there is a stage to make the feedback and reinforcement available. For that purpose the responses to the test-items be clearly justified to be right or wrong with some rationale. So that the students may avoid any confusion and are properly enriched reinforcement with necessary feedback process for the process for the purpose of reinforcement and feedback (Farooq, 1997).

In this perspective it seems very suitable to test and implement modular teaching in our own culture. Besides the importance of biology our students pursue to adopt an effective teaching learning strategy. Therefore a study would be conducted to justify the application of modular teaching in biology. This study was aimed to explore the Effectiveness of Modular teaching in Biology at secondary level" and then to develop modules to be used in teaching of biology. This study would be helpful for the teachers and beneficial for students. Moreover, it would be a useful study for educators and curriculum planners.

\section{Objectives of the Study:}

Following were the main objectives of the study.

1. To determine the role of modular teaching in the academic achievement of students of biology at secondary level.

2. To determine whether the modular teaching is more effective than traditional methods.

3. To recommend for the improvement and promotion of suitable method of teaching biology at secondary level. 


\section{Hypotheses of the Study}

This study was guided by the following Null Hypotheses:

1. There is no significant difference between the mean scores of experimental and control groups on pretest.

2. There is no significant difference between the mean scores of experimental and control groups on posttest.

\section{Research Methodology}

The purpose of this study was to examine the effect of modular teaching on academic achievement of secondary school students in biology. In order to test the relative effectiveness of independent variable, i.e. an instructional paradigm (Modular teaching), the choice of most suitable design for this experiment was the basic step.

Campbell and Stanley (1963) postulate a number of factors, which affect the internal and external validity of experimental designs. Relevant to internal validity, there are eight different factors (these include history, maturation, testing, instrumentation, statistical regression, differential selection, experimental mortality, and selection maturation interaction). If these factors are not controlled in the design, they may produce adverse effects, which confound the effects of the independent variables as shown by the final test scores.

Whereas factors affecting internal validity operate on the scores derived from the dependent variables and, therefore, make the experiment poor as an experiment, factors affecting external validity operate upon the experimental treatments. Campbell and Stanley (1963) postulated four factors, which jeopardize external validity. The pretest-posttest equivalent group design was considered to be the most useful design for this study.

\subsection{Population and Sample}

The aim of this study was to investigate the relative effectiveness of modular teaching on the academic achievement of secondary students in biology. Therefore, students studying the subject of Biology at secondary level constituted the population of study.

Two sections A and B of $9^{\text {th }}$ class of Federal Government Boy's High School Islamabad was taken as sample of the study. Sample students were divided into two groups, i.e. the experimental group and the control group. Both the groups were equated on the basis of pre-test scores. Each group was comprised of 28 students.

\subsection{Research Instruments}

Researcher made pretest and posttest were the research instruments. Both tests were almost parallel with same difficulty level. Each test was composed of multiple choice test items, matching items pertaining to a combination of learning domains. These test items were based on the selected units of $9^{\text {th }}$ class biology (i) Algae and Fungi (ii) Bryophytes (iii) Invertebrates. These three units were taught during the experiment to both the experimental and the control groups, and were intended to measure the learning outcomes. The experiment last for 4 weeks.

\subsection{Validity and Reliability of Test}

The doctoral and subject experts committee of the researcher approved the tests. All the tests items were based on the text of the unit taught to the sample students. The coefficient of reliability was determined through the use of Spearman-Brown Prophecy formula, estimating reliability form the comparable halves of the test, which was found to be 0.75 .

\subsection{Analysis of Data}

Raw scores obtained from pretest and posttest were presented in tabular form for the purpose of interpretation. For the manipulation of data, the means, standard deviations, and differences of means were computed for each group. Significance of difference between the mean scores of both the experimental and control groups on the variable of pretest scores, posttest scores was tested at 0.05 level by applying t-test.

\section{Discussion}

Modular teaching is a new teaching strategy in classroom settings, for arranging learning experiences in education and it has been receiving much attention. The strategy of learning modules has become a part of all level of teaching. A learning module is a self - learning package dealing with one specific subject matter/ unit. It can be used in any setting convenient to the learner and may be completed at the learner's own pace. Sufficient theories and practices are available for the practical application of modular teaching in our classrooms. Therefore a study was conducted in order to check the effectiveness of modular teaching. Obtained data was analyzed, interpreted and conclusions were drawn.

Comparison of pretest scores of both the experimental and the control group by applying statistical analysis reflected that there existed no significant difference between the two groups and both the groups were almost equal 
with respect to biological basic knowledge. Therefore, the null hypothesis, "there is no significant difference between the mean scores of the experimental and control groups on pretest," was accepted at 0.05 level.

The experimental group performed significantly better than the control group on posttest. The difference between the posttest mean scores of the two groups was significant at 0.05 level. Thus the null hypothesis, "there is no significant difference between the academic achievement of the students taught by modular teaching method and the students taught by traditional method of teaching," was rejected at 0.05 level in the favor of the experimental group.

Barnes et al. (2000) investigated that operationalization of modular approach helped in motivating the students and they benefited more from this approach. On the whole, it appears that modular learning group perform significantly better than the group taught by traditional method of teaching. This increased motivation was linked with setting of short-term objectives and the intensity of teaching approach. The Modularization also promoted positive changes in teaching style. The positive results of the study can be examined further by conducting this type of researches in rural areas and in female schools. Before introduction of modular teaching at large scale in schools it is imperative to arrange in-service training of teachers along with preparation of modular instructional material. This study was deficient in respect of content covered and time used. The quality could be improved if more resources were available. Anyhow the results of the study are sufficient for generalization of teaching methods.

\section{Conclusions}

In the light of the statistical analysis and the finding of the study, the following conclusions were drawn.

1 On the whole, modular teaching is more effective as teaching learning process for biology as compared to traditional teaching method. Because in modular teaching the students are provided the opportunities of learning at their own pace, according to their ability level and needs.

2 Students in the modular approach outscored the students working in traditional learning mode have no priority over students taught by traditional method in retaining the learnt biological material. But it could not be generalized. Although basic knowledge of biology of both groups was same in the of data analysis pretest. Overall modular approach is more effective as compared to traditional method.

3 It is a self-learning style in which immediate reinforcement is provided in the form of feedback to practice task, which motivate the student. Hence, the modular approach is considered to create interest among the students as they are free to learn at their own pace.

\section{Recommendations}

In the light of findings and conclusions of the study, following recommendations were made.

1 This study proved that modular teaching is more effective mode of instruction for biology as compared to traditional method of teaching. This method should be applied to others subjects as well as other level of education. Therefore the teachers of biology should use modular teaching to improve the academic achievements of the students.

2 Modular teaching is a new technique in classroom setting, biology teachers should be provided training in module writing and teaching.

3 The results of single study are insufficient to decide about the maximum use of modular approach in our classroom setting. Thus a series of studies on modular approach in different situations and mixed genders at different levels should be carried out.

\section{References}

Barnes, J., P. Mayer, R. Alfred and Hayman. (2000). Modularization of Curriculum at Secondary Level. Kogan Page, London, UK. pp. 67-98.

Brown, J. W., R. B. Lewis and F. F. Harcteroad. (1977). An Instructional Technology, Media, and Methods. McGraw Hill Book Company New York, USA. pp. 21-22.

Campbell, D. T. and J. C. Stanley. (1963). Experimental and Quasi-Experimental Designs for Research on Teaching In N. L. Gage(ed) Handbook of Research on Teaching. Rand McNally and Company, Chicago, USA. P.175.

Daries, I. (1981). Instructional Technology and Media. McGraw Hill Book Company New York, USA. p. 72.

Government of Pakistan. (1988). 7th Five-Year Plan (1988-93) Planning Commission Islamabad, Pakistan. p. 508. 
Government of Pakistan. (1992). National Education Policy, Ministry of Education Islamabad, Pakistan. p. 34. Government of Pakistan. (1993). 8th Five-Year Plan (1993-98) Planning Commission Islamabad, Pakistan. p. 795. Johnson, N. and J. Dalen. (1988). Management and the Psychology of Schooling. The Flamer Press London, UK. p.3.

Loughran, J. and Amanda, B. (2000). Improving Teacher Education Practice through Self Study. Routledge flamer 28 West 35th Street New York, USA. p. 28.

Manlove, D. C. and B. David. (1985). Flexible Scheduling. Longmans Green and Company, New York, USA. pp. 7-12.

Pareek, U. and T. V. Rao. (1981). A Handbook for Trainers in Educational Management. UNESCO Regional Office for Education in Asia and the Pacific Bangkok, Thailand. pp. 189-192.

Taneja, R. (1989). Dictionary of Education. Anmol Publication Murare New Dehli, India. p. 155.

UNESCO. (1988). Developing Instructional Modules for Teacher Education. Regional Office for Education in Asia and Oceania Bangkok, Thailand. pp. 61-63.

Table 1. Significance of difference between mean scores of the experimental and control groups on pretest

\begin{tabular}{|l|c|c|c|c|c|}
\hline Group & $\mathbf{N}$ & $\mathbf{M}$ & $\mathbf{S D}$ & $\mathbf{S E}_{\mathbf{D}}$ & $\boldsymbol{t}$ value \\
\hline Experimental Group & 28 & 34.50 & 6.32 & \multirow{2}{*}{1.68} & $0.22 *$ \\
\hline Control Group & 28 & 34.14 & 6.22 & & \\
\hline
\end{tabular}

* Not significant $\quad \mathrm{df}=54 \quad t$ - value at 0.05 level $=2.01$

Table 1 indicates that the difference between the mean scores of the experimental group and control groups on pretest was found to be insignificant at 0.05 level. Because the obtained t-value is 0.22 , which is less than the table value. Hence, the null hypothesis, "there is no significant difference between the mean scores of experimental and control groups on pretest" was accepted and both the groups could be treated as equal.

Table 2. Significance of difference between mean scores of the experimental and the control groups on posttest

\begin{tabular}{|l|c|c|c|c|c|}
\hline Groups & $\mathbf{N}$ & $\mathbf{M}$ & $\mathbf{S D}$ & SE $_{\mathbf{D}}$ & $\boldsymbol{t}$ - value \\
\hline Experimental Group & 28 & 67.71 & 9.97 & \multirow{2}{*}{2.80} & \multirow{2}{*}{$4.48^{*}$} \\
\cline { 1 - 5 } Control Group & 28 & 55.39 & 11.02 & & \\
\hline *Significant df $=54$ & $t$-value at $0.05=2.01$
\end{tabular}

Table 2 indicates that the difference between mean scores of the experimental and the control groups on posttest was found to be significant at 0.05 level. Hence, the null hypothesis, " there is no significant difference between the mean scores of experimental and control group on posttest", was rejected, in the light of t-value obtained which is greater than the, table value at 0.05 level which is significant at 0.05 level. Hence, the null hypothesis was rejected. At posttest performance of experimental group was better than control group. These results support the concept of Pareek and Rao (1981), that modular approach creates interest in the individuals and they demonstrated significantly higher achievements than the individuals taught by traditional approach. 